\title{
PROTON-INDUCED DEGRADATION OF THIN-FILM MICROCRYSTALLINE SILICON SOLAR CELLS
}

\author{
F. Meillaud, E. Vallat-Sauvain, X. Niquille, M. Dubey, A.Shah, C. Ballif \\ Institute of Microtechnology IMT, Breguet 2, CH-2000 Neuchâtel (Switzerland) \\ Phone: +41.32.718.33.19, Fax: +41.32.719.32.01; e-mail: fanny.meillaud@unine.ch
}

\begin{abstract}
This paper investigates the stability of dilution series of pin and nip microcrystalline silicon solar cells under low-energy proton irradiation $(\mathrm{E}=405 \mathrm{keV})$. Variation of electrical parameters, defect-related absorption and Urbach parameter are investigated as a function of irradiation and annealing steps. Highly microcrystalline cells show a relative efficiency loss of up to $80 \%$ after proton irradiation. The efficiency loss is observed not to be completely reversible under thermal annealing. Increase of defect-related absorption and Urbach parameter is also only partially reversible. The electrical parameters $\left(\mathrm{J}_{\mathrm{sc}}, \mathrm{V}_{\mathrm{oc}}, \mathrm{FF}\right)$ show proton-induced reductions which increase with crystallinity for both pin and nip series; short-circuit current density suffers the largest variations with relative losses of up to 65\%. Defect-related absorption is shown to be low for cells of medium crystallinity, before and after irradiation.
\end{abstract}

PACS codes : 72.40.+w ; 61.80.-x

\section{Introduction}

Amorphous silicon solar cells are known to present better stability against high-energy (1-20 MeV) proton radiation [1, 2, 3] compared with mono-crystalline silicon devices [3]. Microcrystalline silicon solar cells were shown to suffer from degradation when exposed to protons of energy within this range [2]. This behavior is opposite to that observed when a-Si:H and $\mu \mathrm{c}-\mathrm{Si}: \mathrm{H}$ silicon solar cells are exposed to lightsoaking $[2,4]$. Therefore, in this study the stability of thin-film $\mu \mathrm{c}-\mathrm{Si}: \mathrm{H}$ solar cells under proton radiation is investigated as a complementary study to light-soaking experiments [4], in order to clarify the effect of both light-induced and proton-induced defects and gain further physical insight. In contrast to previous 
work $[1,2,3]$ the proton energy used in our study is lower, i.e. $405 \mathrm{keV}$, in order to achieve proton implantation within the first micrometer of the intrinsic layer, instead of merely letting the protons pass through the device [5]. The damage created by the proton irradiation within the devices is, thus, maximized and we obtain complementary information as compared to that given in $[1,2,3]$.

\section{Experimental}

\subsection{Samples}

Two dilution series of pin and nip $\mu c-S i: H$ cells were deposited by VHF-PECVD on LP-CVD ZnO /glass substrates [6]. The silane concentration used for the deposition of the intrinsic layer was varied, whereas the deposition parameters of the doped layers were kept constant within each series. The resulting i-layer average crystallinity $\phi_{c}$, as evaluated from Raman measurements [7], is between $10 \%$ and $81 \%$ for the pin series (i-layer $\sim 1.5 \mu \mathrm{m}$ ) and between $22 \%$ and $62 \%$ for the nip series (i-layer $\sim 2.2 \mu \mathrm{m}$ ). The pin and nip series were deposited in two different systems, a single-chamber and a double-chamber system, respectively. Both series were irradiated with a $405 \mathrm{keV}$ proton beam from a Van der Graaf accelerator (initial $\mathrm{p}^{+}$beam of $1.07 \mathrm{MeV}$ attenuated through a $12 \mu \mathrm{m}$ aluminum foil) and a fluence of $2.510^{13} \mathrm{p}^{+} / \mathrm{cm}^{2}$. After irradiation, annealing steps of $10 \mathrm{~h}$ were carried out, under nitrogen flow, at increasing temperatures: $70^{\circ} \mathrm{C}, 100^{\circ} \mathrm{C}, 130^{\circ} \mathrm{C}, 160^{\circ} \mathrm{C}$ and $180^{\circ} \mathrm{C}$.

\subsection{Characterization techniques}

Open-circuit voltage $\left(\mathrm{V}_{\mathrm{oc}}\right)$ and fill factor $(\mathrm{FF})$ were obtained from $\mathrm{I}(\mathrm{V})$ measurements under an $\mathrm{AM} 1.5$ sun simulator at $25^{\circ} \mathrm{C}$, whereas short-circuit current density $\left(\mathrm{J}_{\mathrm{sc}}\right)$ was obtained from external quantum efficiency measurements. The Fourier transform photocurrent spectroscopy (FTPS) technique was used to measure sub-bandgap absorption spectra of the i layers as incorporated within the solar cells; the setup and measurement conditions are described in detail in [8]. According to [8], defect-related absorption is given by the absorption coefficient as measured at $0.8 \mathrm{eV}$. The FTPS spectra measured in this study were calibrated at $1.35 \mathrm{eV}$, by setting the absorption coefficient of the $\mu \mathrm{c}-\mathrm{Si}: \mathrm{H}$ cells to the value of crystalline silicon $\left(245 \mathrm{~cm}^{-1}\right)$. With this calibration procedure, defect-related absorption can be reasonably assumed to 
originate only from the defects within the crystalline phase $[4,9]$. The Urbach parameter $\mathrm{E}_{0}$ is established from the slope of the absorption spectra between 0.98 and $1.08 \mathrm{eV}$. Micro-Raman spectroscopy performed with a HeNe laser excitation beam $(633 \mathrm{~nm})$ was used to evaluate the average crystallinity of the intrinsic layer, calculated as the arithmetical average of the Raman crystallinity factor as measured from the top and bottom of the samples [7].

\section{Results}

\subsection{Electrical parameters}

The effect of proton radiation on the efficiency of the solar cells is presented in Fig. 1, with the relative efficiency loss $\Delta \eta$ plotted as a function of the i-layer average crystallinity $\phi_{c} . \Delta \eta$ is defined as:

$$
\Delta \eta=\left(\eta_{\text {initial }}-\eta_{\text {irradiated }}\right) / \eta_{\text {initial }}
$$

Pin and nip series present similar trends with $\Delta \eta$ increasing as a function of $\phi_{c}$; a slightly larger relative degradation is observed for the pin series, especially for cells of low crystallinity. Highly $\mu \mathrm{c}-\mathrm{Si}: \mathrm{H}$ cells are shown to suffer from a very strong degradation with a relative efficiency decrease of up to $80 \%$, while highly a-Si:H cells show a relative efficiency reduction of around $30 \%$. Relative losses of $\mathrm{V}_{\mathrm{oc}}, \mathrm{FF}$ and $\mathrm{J}_{\mathrm{sc}}$ are also observed to increase with increasing i-layer crystallinity; $\mathrm{J}_{\mathrm{sc}}$ is the parameter that is the most affected by proton irradiation. A relative decrease of $\mathrm{J}_{\mathrm{sc}}$ of $51 \%$ is, thus, measured for the nip cell with the highest crystallinity, together with a relative decrease of $\mathrm{FF}$ and $\mathrm{V}_{\mathrm{oc}}$ of $22 \%$ and $15 \%$, resp. The relative loss of $\mathrm{J}_{\mathrm{sc}}$ is presented as a function of wavelength in Fig. 2 with the external quantum efficiency curves (EQE), in initial state, after irradiation and after annealing at $180^{\circ} \mathrm{C}$, for the highly crystalline nip cell $\left(\phi_{\mathrm{c}}=\right.$

$62 \%)$. It is observed that $\mathrm{EQE}$ is reduced over the whole wavelength range by $\mathrm{p}^{+}$irradiation, with the main reduction occurring in the long wavelength response. Furthermore, the reduction of EQE is only partially reversible under the thermal annealing steps performed.

3.2 FTPS spectra and defect-related absorption

The relationship between defect-related absorption $(\alpha(0.8 \mathrm{eV}))$, in initial and irradiated states, and crystallinity is presented in Fig. 3 for the nip series. The trend is similar for the pin series (not shown 
here). The $62 \%$ crystalline nip cell shows an increase of $\alpha(0.8 \mathrm{eV})$ of a factor 10 , while $\alpha(0.8 \mathrm{eV})$ is lower for the solar cells with $\phi_{\mathrm{c}}$ between 40 and $50 \%$.

\subsection{Annealing}

The effect of subsequent annealing steps on the normalized efficiency can be seen in Fig. 4, again for the nip series. Normalized efficiency is defined as $\eta$ (after irradiation/annealing) over $\eta$ in the initial state. We observe that the largest recovery mainly occurs after the annealing steps at $70^{\circ} \mathrm{C}$ and $100^{\circ} \mathrm{C}$. Total recovery is not observed, even after annealing at $180^{\circ} \mathrm{C}$. Normalized defect-related absorption presents a similar trend (not shown here). Fig. 5 shows $\alpha(0.8 \mathrm{eV})$ and the Urbach parameter $\mathrm{E}_{0}$ as a function of irradiation and annealing steps for the $62 \%$ crystalline nip cell: we observe that both parameters vary in a very similar way, and, after annealing at $180^{\circ} \mathrm{C}$, neither $\alpha(0.8 \mathrm{eV})$ nor $\mathrm{E}_{0}$ return to their initial values.

\section{Discussion}

In the experiments presented above, we show that the higher the crystallinity, the lower is the protonrelated stability of microcrystalline silicon solar cells. A slightly larger relative degradation is observed for the pin series, compared with the nip series. It should however be mentioned that the average initial efficiency of the pin series is lower than that of the nip series. And, as was moreover suggested in [4], this particular pin series may suffer from contamination. Short-circuit current density is the parameter that is the most affected by proton irradiation: this is due to the reduced external quantum efficiency over the whole wavelength range, with the main reduction occurring in the long wavelength response. We assume that the short wavelength decrease of the $\mathrm{EQE}$ is a consequence of the proton implantation at the $\mathrm{p}-\mathrm{i}$ interface, while the long wavelength reduction results from the increase of recombination centers density, as evidenced by the FTPS absorption spectra. The decrease of external quantum efficiency is observed not to be completely reversible under the thermal annealing steps performed. These observations, as well as the strong deterioration of electrical parameters observed here (stronger than in the case of high-energy proton, see [2]), confirms that the implantation of the low energy protons is much more destructive than exposure to protons with higher energies. The implantation depth of the protons was estimated at $1 \mu \mathrm{m}$ 
from a calculation using SRIM (Stopping and Range of Ions Matter) software [10]. Defect-related absorption $\alpha(0.8 \mathrm{eV})$ is lower for the solar cells with $\phi_{\mathrm{c}}$ between 40 and $50 \%$, as compared to cells of higher crystallinity. This trend is observed both in initial and $\mathrm{p}^{+}-$degraded state. A similar optimum was observed when the same series were exposed to light soaking [4]. It is also observed for highly microcrystalline solar cells (see e.g the $62 \%$ crystalline nip cell) that $\alpha(0.8 \mathrm{eV})$ and the Urbach parameter $\mathrm{E}_{0}$ do not return to their initial value, even after the last annealing step. This suggests that the proton implantation (i.e hydrogen implantation) dos not only lead to the creation of deep defects but also to damage related to the bandtail states.

\section{Conclusions}

Pin and nip microcrystalline silicon solar cells are shown to suffer from a strong degradation when exposed to low-energy protons which are implanted in the first micrometer of the intrinsic layer. The damage as created by these implanted protons is shown to be only partially reversible under thermal annealing steps up to $180^{\circ} \mathrm{C}$, contrary to light-induced degradation. Also, $\mathrm{p}^{+}$-induced degradation is shown to be stronger the higher the crystallinity within the i-layer. We suggest that the short-circuit current density reduction after irradiation is due to an increase of the recombination centers, as well as the presence of proton-related defects at the p-i interface. It is also observed that $\alpha(0.8 \mathrm{eV})$ and $\mathrm{E}_{0}$ increase with $\mathrm{p}^{+}$-irradiation and never return to their initial values. This suggests that low-energy protons create defects that affect both deep defects and bandtail states. Finally, defect-related absorption $\alpha(0.8 \mathrm{eV})$ is observed to be lower for cells of medium crystallinity, in initial but also degraded state; a similar trend had been observed for light-soaking on the same series of cells [4].

\section{Acknowledgements}

The authors thank Yvan Gonin and the CAFI (Ion Beam Analysis Center, Le Locle, Switzerland) for the proton radiation campaign. This work was supported by the Swiss National Foundation (FN-66985) and the Swiss Federal Office for Energy (100 045).

\section{References}


[1] S. Guha et al, J. Yang, A. Banerjee, T. Glatfelder, G.J. Vendura, A. Garcia, M. Kruer, Proc. of the $2^{\text {nd }}$ WCPEC, Vienna. Austria, 1998, 3609

[2] J. Kuendig, M. Goetz, A. Shah, L. Gerlach, E. Fernandez, Solar Energy Materials and Solar Cells 79 (2003) 425

[3] G. J. Vendura Jr., C.M.C Toporow, M.A. Kruer, Proc. of the $2^{\text {nd }}$ WCPEC, Vienna, Austria, 1998, 3745

[4] F. Meillaud, E. Vallat-Sauvain, X. Niquille, M. Duubey, J. Bailat, A. Shah, C. Ballif, Proc. of the $31^{\text {st }}$ IEEE, Orlando, FL, USA, 2005, 1412

[5] N. Wyrsch, C. Miazza, S. Dunand, C. Ballif, A. Shah, M. Despeisse, D. Moraes, P. Jarron, Proc. of the Mat. Res. Soc. Spring Meeting, San Francisco, April 2005, MRS Vol. 862, 2005, A15-4

[6] S Faÿ, U. Kroll, C. Bucher, E. Vallat-Sauvain, A. Shah, Solar Energy Material \& Solar Cells, 86 (2005) 385

[7] C. Droz, E. Vallat-Sauvain, J. Bailat, L. Feitknecht, J. Meier, A. Shah, Solar energy Material and Solar Cells, 81(2004) 61

[8] M. Vanecek and A. Poruba, Applied Physics Letter, 80 (2002) 719

[9] J. Bailat, A. Poruba, L. Mullerova, J. Springer, M. Vanecek, E. Vallat-Sauvain, F. Meillaud, X. Niquille, M. Dubey, S. Rosset, J. Guillet, L. Feitknecht, A. Shah, , Proc. of the $19^{\text {th }}$ EUPVSC, Paris, France, 2004, 1541

[10] Nicolas Wyrsch, F. Finger, T. J. McMahon, M. Vanecek, J. of Non-Cryst. Solids, 137\&138 (1991), 431 


\section{Figure captions}

Fig.1. Relative proton-induced loss of efficiency versus i-layer crystallinity for both series of cells. Dashed lines are only a guide to the eye.

Fig.2. External quantum efficiency measurement in initial and irradiated states and after the annealing at $180^{\circ} \mathrm{C}$ for the $62 \%$ crystalline nip cell

Fig.3. Defect-related absorption in initial and irradiated state as a function of the i-layer crystallinity for the nip series. Dashed lines are only a guide to the eye.

Fig.4. Normalized efficiency as a function of irradiation and subsequent annealing steps for the nip series. Fig. 5 Defect-related absorption and Urbach parameter as a function of proton irradiation and subsequent annealing steps for the $62 \%$ crystalline nip cell 


\section{Figures}

Fig.1.

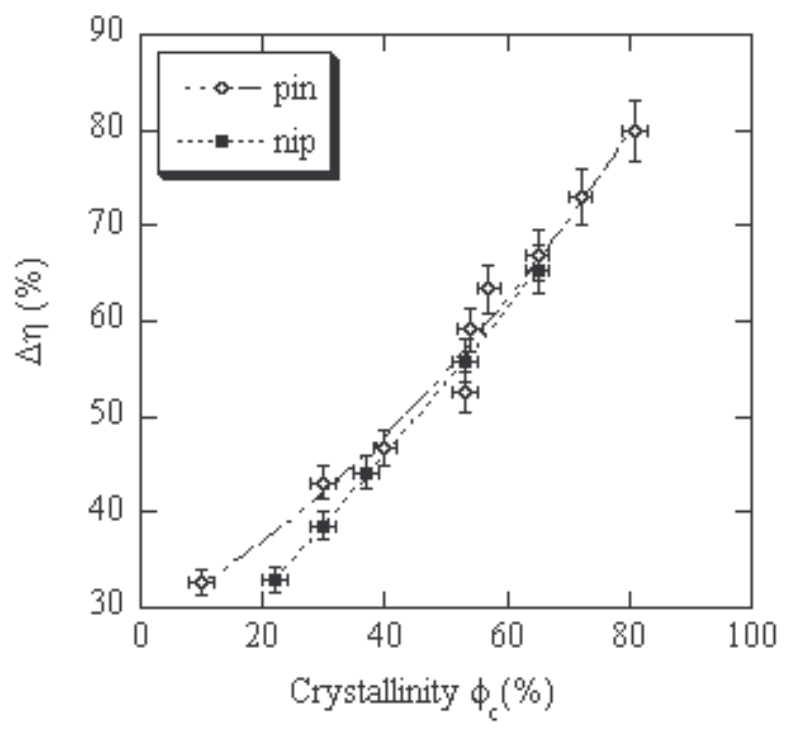

Fig.2.

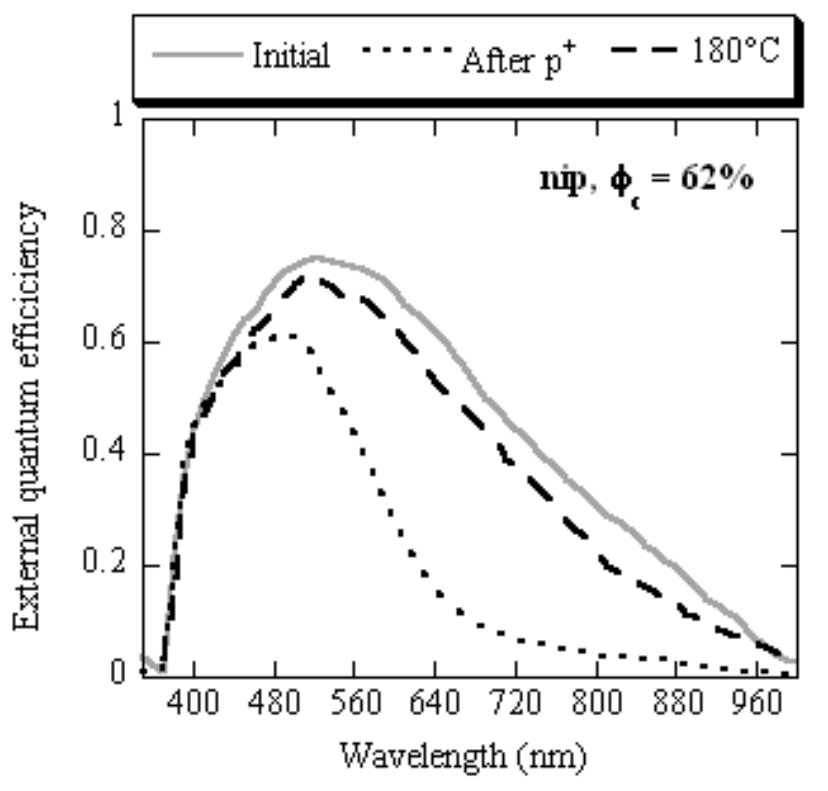


Fig. 3.

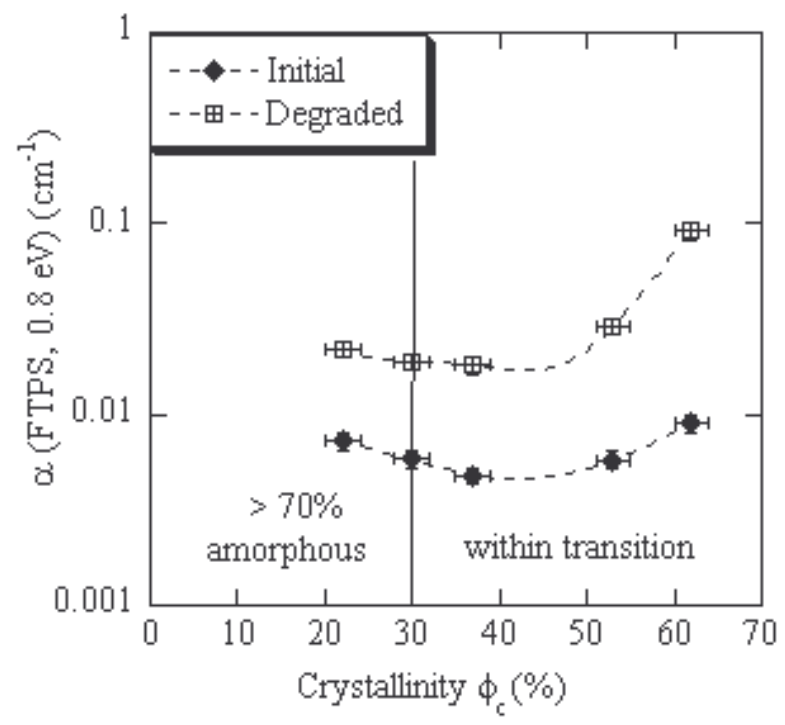

Fig.4.

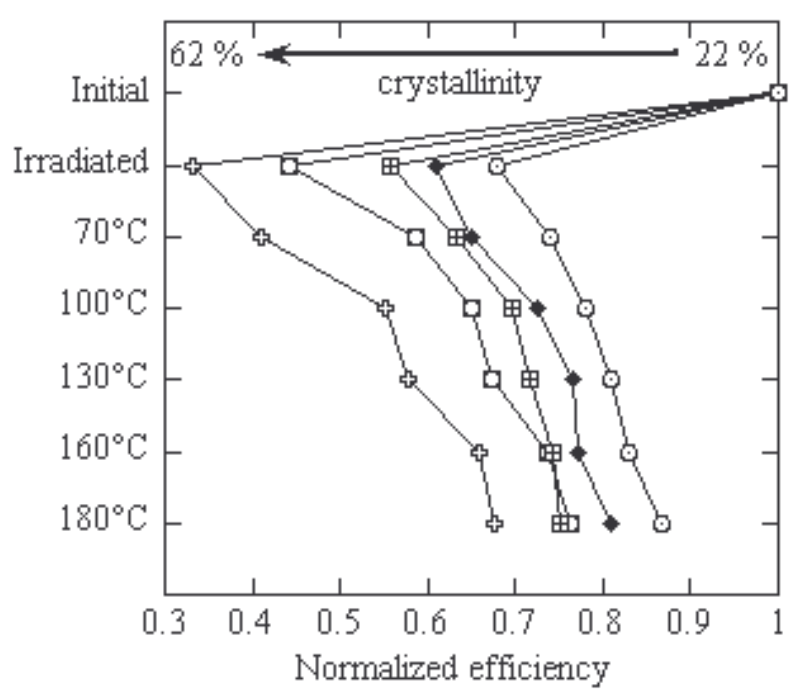


Fig. 5

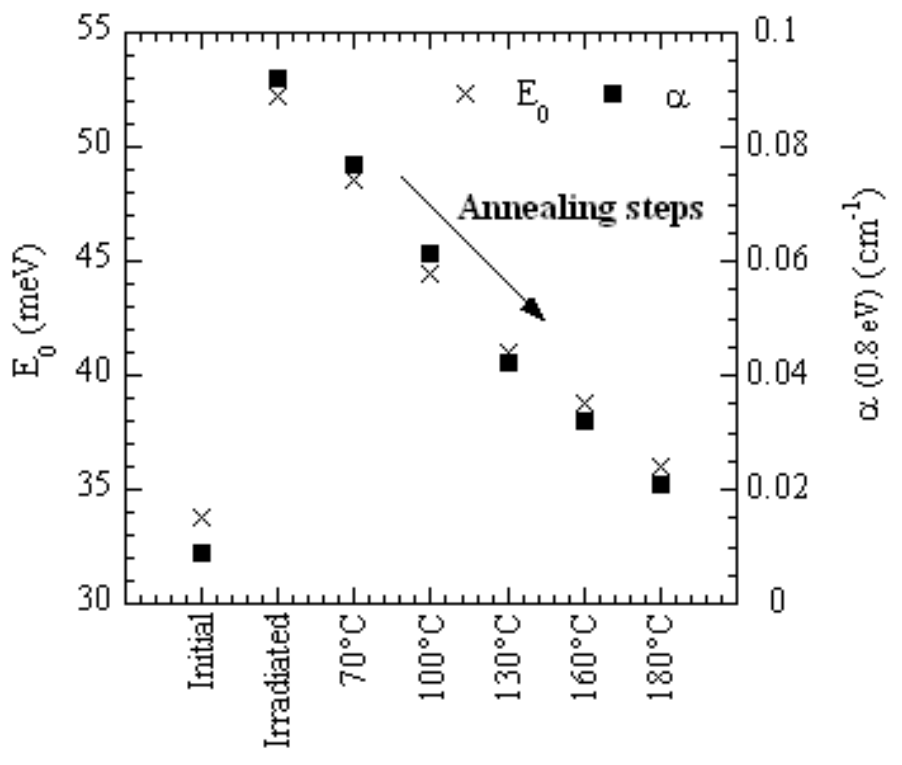

